\title{
Study on Programming of CNC Turning and Processing Techniques
}

\author{
Guofu Zhang ${ }^{1}$, Xiuling Wang ${ }^{1}$ \\ ${ }^{1}$ College of Humanities and Information, Changchun \\ University of Technology, Changchun, Jilin, 130122 China.
}

\author{
Hongyan Shen ${ }^{2}$ \\ ${ }^{2}$ Jilin Russian College, Changchun, Jilin, 130000 China
}

\begin{abstract}
Due to its high efficiency, high precision and high flexibility, CNC lathe is widely used in the machinery manufacturing industry increasingly, and becomes one of CNC machine too[s that most widely used. However, to give full play to the role of CNC lathes, the key is program, that is, preparing the reasonable and efficient processing procedures depending on the features and precision parts. This paper discussed the problems of programming and processing techniques of the CNC lathe parts.
\end{abstract}

Keywords-Machine tool origin; Reference point of machine; $G$ code instructions; Dimensional accuracy

\section{INTRODUCTION}

In China, the Independent Colleges Undergraduate Education is an important part of the modern national education system and college fully implement the Party's education policy, to serve for the purpose of employmentoriented, and strive to achieve the "Engineer Technician" training objectives (students trained to the basic ability with mechanical engineers and technicians the application of practical skills talent). Implementation of the dual permit system to extract the typical tasks, the typical products or services in accordance with the requirements of the vocational qualification certificate corresponding positions, and then analyzes come to the professional core skills, job core skills, then these core skills of decomposition, and finally to develop the professional personnel training programs. CNC turning programming and processing of teaching in our hospital is such a large context of deepening reform, set to open. Real jobs, build the teaching objectives; as the carrier of the real parts to build the teaching content; real process to build a teaching model; combination of assessment methods to the real level of skill, to build the process of assessment and professional accreditation. To ensure that the premise of the quality of teaching, deepening reform, the implementation of $\mathrm{CNC}$ turning programming and machining teaching.

\section{The Positioning OF Personnel Training Mode}

Written in the traditional lecture notes are often like a "test specification", the lack of students' ability to think independently, rich imagination, engineering and testing capacity, the innovative sense, poor teaching results [1]. College take full advantage of the specialized laboratories Engineering Training Centre - off-campus practice bases to enhance students' professional skills development, the progressive realization of the market "distance" docking. CNC programming and machining teaching, to adjust the teaching program, as the core of practical teaching reform, open to the practice of resource sharing based, high-quality practice teaching team and a complete practice teaching conditions, resources, innovation and operational mechanism. "7S" management and project teaching, process guidance, the implementation of the "strong" application has its own characteristics, personnel training mode.

\section{CNC TURning Programming AND Machining TEACHING SITUATION}

Antiquated teaching models and methods of traditional CNC turning programming and processing teaching, teaching reform and keep up with the needs of the times, job orientation is not clear, and miscellaneous knowledge, not very conducive to the students to master; imbalance of theory and practice lessons, the teaching project typical not, students are unable to digest, comprehensive ability, the gap between students' professionalism and corporate requirements

\section{CNC Turning Programming ANd Processing TEACHING}

CNC programming and machining mechanical Practical strong core curriculum. With the deepening of the reform of higher education, the training of the student's sense of innovation and engineering practice is becoming an important part of teaching reform. Find the greatest satisfaction of the students hands-on teaching reform needs, but also to some extent, reduce material waste "post simulate machining simulation" and "combat training" a combination of means to achieve "strong" application personnel purposes. CNC programming courses for improving teaching, and take a series of effective measures. Such as: the real reason one teaching, "7S" management, project teaching, process guidance.

\section{A. Teaching of Theory and Practice of One}

Eastern and Western cultures have many differences, the educational system is also different. Nuremberg, Germany, Technical University of the German Technical University to implement segmented teaching curriculum to broaden the basis of, desalination professional boundaries. This model, mainly for business and schools, the close integration of practical skills and theoretical knowledge, that is, practice - theory - practice - then the theory of circulation teaching model. And so forth from practice to theory, and from the continuous cycle of theory to practice, spiral, so that the level of knowledge to continuously 
improve, this approach is entirely consistent with the human knowledge of the law of objective things. CNC turning programming and processing teaching using the integration of theory and practice of teaching.

\section{B. "7S" management practice teaching, to achieve "strong" culture}

Enterprises require workers not only have a certain professional skills and job skills, but also with a certain sense of security, professional quality and teamwork. In order to strengthen organizational leadership, and strengthen the teaching of management and steering mechanisms, training centers to conduct an overall effective macro-control, "7S" management to build a scientific and orderly operation mechanism to ensure that teaching successfully carried out. "7S" management is a dynamic management system, "7S" management to achieve efficient, civilized and orderly $\mathrm{CNC}$ turning and practice of state, while students of all aspects of the competence and quality, effectively ensuring the teaching process smooth and efficient to further improve the management level of engineering training center, to facilitate students' training will help to achieve the "two powers".

\section{The concrete implementation of the "7S" management in the training process}

Training specific to explain before the "7S" management of the content and implementation of the significance, and then implement all aspects of training. Number of lathes, tools, measuring tools, fixtures, bundled with the lathe. From entering engineering training center every day to carry out the "7S" management. Points of time, step by step, sub-regional training management, so that students in accordance with the requirements of practice and develop good safety and production habits of civilization. [2]

\section{Implementation of the project teaching, strengthening process management}

1) To improve the teaching mode, the use of diverse teaching methods. The training center assisted practice teaching, integration of a variety of ways to make full use of multimedia, electronic teaching tools, the use of computer networks, programming teaching and the use of simulation software, and mold aids, and practical operation and simulation, combining lectures and visual aids, demonstration teaching combined to observe the teaching, the better to enhance the effect of theoretical teaching and practical teaching.

2) The implementation of Project Approach. In accordance with the chapter in the textbook knowledge to explain, it is difficult to the teaching of theory and practice integration process. Reconstruct the teaching content, teaching highlight the practicality of the teaching content, practical. Task-driven, project pedagogy. It not only has the scientific and systematic characteristics, but also with the integration of theory and practice, the characteristics of the industry of business services, emphasizing the cultivation of students' practical skills and ability. The teacher is no longer an encyclopedia for students to use the database to become a wizard and consultants to provide students with a working practical operation of the guidelines and guidance to the student internship. [3-4]

3) Determine the learning process-based projects to enhance the teaching process control. In order to ensure the implementation of the plan of practical teaching and guarantee the quality of teaching, we must strengthen the practical teaching of process control, content design is no longer the sole objective to teach students knowledge, and strengthen the process guidance, guide students to the knowledge used in the actual work being as the main objective. Process control of practical teaching activities, one practical teaching activities ongoing in accordance with the established teaching plans and objectives; teachers and students can understand the capacity and efficiency of the implementation of practical teaching program, and timely amendments to the practical teaching programs, and timely innovation [5].

\section{REASONABLE TO BUILD THE STRUCTURE OF TEACHERS, TRAINING THREE QUALIFIED TEACHERS, SCIENCE AND DESIGN TRAINING PROJECTS}

Meet the requirements for the training of the "strong" students, and build a two-teacher team is critical, the training of teachers, upgrading is essential. Engineering training center actively recruit experienced retired teachers, but also "Double Type" within training Waiyin the "on the basis of positive culture and the introduction of three qualified teachers. Training modules on a regular basis to carry out reform, science, the rational design of training topics, process optimization [6]. Follow the laws governing the development of students' abilities, in accordance with the principles of Deep, from easy to difficult, the rational design of the link between each training topic [7].

\section{SCHOOL-ENTERPRISE COOPERATION, STRENGTHEN EXCHANGES AND TRAINING}

Typical examples of projects of development to build courses, cooperation with enterprises as the core of the shelf life of processed full amount of dedication and innovative spirit to develop focus, to post work to build a CNC turning programming and processing of learning content. Take "teachers into the enterprise, the experts into the classroom to develop the CNC turning programming and processing standards of teaching, curriculum design, to create a true Kong practical operation of engineering teaching model in combination. Expose students to the actual processing of the workpiece, it will not only be able to improve students 'proficiency in the operation also fosters students' awareness of product quality awareness, awareness. 


\section{CONCLUSIONS}

$\mathrm{CNC}$ turning programming and processing teaching is a combination of a theoretical and practical issues, hospital research in accordance with the current development of undergraduate education teaching philosophy of Independent Colleges and accurate positioning CNC turning teaching training objectives, the main line with the core skills through a series of effective measures to improving teaching, good teaching.

\section{REFERENCES}

[1] Shuangli Li. "Ordinary lathe" open training teaching model of Guangdong University of Technology[J]. (Social Science Edition), Vol.10, Supplement, pp.214 -215, July 2010.

[2] Yaoxing Shen. "7S" management practice in the the turner Training $[\mathrm{J}]$. China: Secondary vocational education. pp.23-24, May 2011.
[3] Jinfeng Zhao and Qiuxia Chen. Tool selection and ordinary lathe Curriculum Reform in Analysis[J]. China Educational Technology \& Equipment December 2011,3(5), total: 221, pp.109-110.

[4] Qiong Hu. On the job page and project teaching sewing training course[J]. Fujian Building Materials. 2011, Fifth, total: 124, pp.117119.

[5] Hande WU. Vigorously promote the the TVU practical teaching - Wu Hande comrades speech in the TVU practice teaching at the work site to a new level [DB / OL]

[6] 2004-12-18/2012-2-7 http://tieba.baidu.com/f?kz=106477577.

[7] Zhijian Qiu. Analysis on how to reduce the cost of training teaching skills, improve the quality of teaching[J]. Value engineering, pp.20, April, 2011.

[8] Qirong Feng and Ying Zhao. Discussion on technical school electricity class specialized in how to reduce the training cost[J]. Teaching and research. pp.62-63, March, 2011. 